\title{
Designing Active Sites for Structure-Sensitive Reactions via the Generalized Coordination Number: Application to Alcohol Dehydrogenation
}

\author{
Kamila Ká́mierczak, Paul Clabaut, Ruben Staub, Noémie Perret, Stephan N. Steinmann, \\ and Carine Michel*
}

ABSTRACT: Identifying the structure of the most active site is essential to improve the performance of supported metal catalysts. For structure-sensitive reactions, in silico design cannot be easily achieved combining the scaling relations and Brønsted-Evans -Polanyi relations, which are only built on energy-based descriptors. We used here the generalized coordination number as a structural descriptor and established that low-coordinated sites are desirable when using Co and Cu to perform the acceptor-less alcohol dehydrogenation reaction.

\section{INTRODUCTION}

Computational approaches are recognized as essential to accelerate the design of improved metal-based supported catalysts. ${ }^{1,2}$ A typical strategy is to first investigate the reaction mechanism of a series of pure transition-metal surfaces and then to screen for an alloy combination of improved activity. $^{3-6}$ The predicted activity for alloys is extrapolated from the one for pure metals using descriptors that are typically energy-based (e.g., adsorption energy of a representative species). For instance, this extrapolation can be performed combining linear-scaling relations, ${ }^{7-10}$ which relate the adsorption energy of reaction species to the corresponding atomic fragments, and Brønsted-Evans-Polanyi (BEP) relationships, ${ }^{11-14}$ which predict the activation energy from the reaction energy. Inserting these relations in a microkinetics framework, a turnover frequency (TOF) can be computed as a function of the energy-based descriptors in a $1 \mathrm{D}$ or $2 \mathrm{D}$ volcano plot. ${ }^{4,5,15}$ This in silico design predicts alloys that are active but not necessarily feasible to prepare. Even worse, due to the universality of the scaling relationships, ${ }^{16-18}$ the top of the predicted volcano plot may still feature rather inactive catalysts (in $1 \mathrm{D}$ volcano plots) or may lie in a zone that cannot be reached by the (linear) combinations of transition metals (in $2 \mathrm{D}$ volcano plots). ${ }^{15}$ Hence, to overpass the top of the predicted volcano, it is crucial to identify systems that are not obeying those linear scaling relationships. ${ }^{19-21}$ Several alternatives can be explored, such as strain, ${ }^{22}$ ensemble effects in alloys, ${ }^{23-25}$ interfacial sites with the support, ${ }^{26}$ and surface decoration, $^{27-29}$ and for structure sensitive reactions, ${ }^{30}$ the nanoparticle size and shape. ${ }^{7,31}$ In the last case, using a structural descriptor rather than an energy-based one appears as a natural choice, as it is directly related to the (local) shape of the active site. To this purpose, Calle-Vallejo et al. recently introduced the generalized coordination number (GCN) predicting with success better sites for the oxygen reduction reaction, ${ }^{32-34}$ including strain, ${ }^{35}$ but also for the structuresensitive acetone electroreduction. ${ }^{36}$ It was also recently used to design optimal active sites on $\mathrm{Cu}$ for the structure-sensitive $\mathrm{CO}_{2}$ electroreduction. ${ }^{37} \mathrm{GCN}$ is a generalization of the coordination number of an atom that takes into account not only the first-coordination shell of the surface metal atom, but also its second-coordination shell. It allows a fine geometrical description of metal surfaces. For instance, GCN can distinguish terrace sites depending on the distance to the edge because it decreases when getting closer to the edge.

In this article, we investigate the structure sensitivity of acceptor-less alcohol dehydrogenation (AAD), a key reaction to upgrade biomass that generates added value carbonyls and gaseous hydrogen. ${ }^{38}$ The metal catalyst activity was shown to depend on the size of the metal nanoparticles, ${ }^{39-42}$ an effect that can be ascribed to a greater metal/support interface or to a greater exposure of undercoordinated sites on the metal nanoparticles. Here, we focus on the example of $\mathrm{Co}$ and $\mathrm{Cu}$, two abundant $3 \mathrm{~d}$ transition metals featuring very different properties, and recently demonstrated to be active in the AAD reaction. ${ }^{30,43-46,29,47,48} \mathrm{Co}$ is a reactive $\mathrm{d}^{7}$ metal with a strong affinity toward $\mathrm{H}, \mathrm{C}$, and $\mathrm{O}$, while $\mathrm{Cu}$ is a coinage metal with a 
weaker affinity due to its $\mathrm{s}^{1} \mathrm{~d}^{10}$ electron configuration. Recently, combined experimental and density functional theory (DFT) studies demonstrated that the $\mathrm{Cu}(211)$ surface was more active than the $\mathrm{Cu}(111)$ close-packed surface to perform the gas-phase dehydrogenation of ethanol. ${ }^{49}$ Our previous DFT studies predicted a similar trend for Co with the open type $\mathrm{Co}(11-20)$ surface being more active than the close-packed $\mathrm{Co}(0001)$ surface. ${ }^{50}$ To probe the structure sensitivity of alcohol dehydrogenation more extensively, we have chosen here to explore the dehydrogenation of a prototypical alcohol (isopropanol) on the most exposed facets on hcp Co, fcc Co, and fcc $\mathrm{Cu}$ particles according to a Wulff reconstruction. ${ }^{51,52}$ Building on this extensive set of data, we first investigated the ability of linear-scaling relations and BEP relationships to predict the activity on a variety of $\mathrm{Co}$ and $\mathrm{Cu}$ facets. Then, we exploited the GCN structural descriptor to capture the structure sensitivity of alcohol dehydrogenation and finally design the most active site structure of $\mathrm{Co}$ and $\mathrm{Cu}$ catalysts.

\section{METHODS}

DFT Computational Details. Periodic DFT computations were performed with the Vienna $\mathrm{Ab}$ initio Simulation Package (VASP) (version 5.3.5). ${ }^{53,54}$ The exchange-correlation energy and potential were calculated with the generalized gradient approximation (GGA) using the PBE functional ${ }^{55}$ with the $\mathrm{dDsC}$ dispersion correction, ${ }^{56,57}$ a combination that was proved to be the most accurate to describe the adsorption of molecules on metal surfaces. ${ }^{58}$ The projector augmented wave method (PAW $)^{59,60}$ was used to describe the electron-ion interactions. A cut-off energy of $400 \mathrm{eV}$ was applied to obtain a tight convergence of the plane-wave expansion. Electronic energies were obtained with a convergence criterion of $10^{-6}$ $\mathrm{eV}$.

The optimal interatomic $\mathrm{Co}-\mathrm{Co}$ distance was established for bulk hcp Co and was found to be equal to $2.47 \AA$ (in agreement with an experimental value of $2.51 \AA$, the c lattice parameter was counted according to the experimental proportion and was equal to $4.01 \AA$ ), and further used for all the surfaces. For $\mathrm{Cu}$, the optimal interatomic distance was established for fcc $\mathrm{Cu}$ and found to be equal to $3.62 \AA$ (in excellent agreement with the experimental value of $3.615 \AA$ ). The catalyst surfaces were represented by nonsymmetric slabs, composed of few metal layers (usually 4) separated by a vacuum of over $10 \AA$. . Half of the layers (bottom layers) were fixed in bulk truncated positions, whereas the remaining half (upper layers) were allowed to relax. All the computations were performed with dipole correction in the $z$ direction perpendicular to the surface. Five hcp type surfaces and four fcc type facets of $\mathrm{Co}$, and four fcc type surfaces of $\mathrm{Cu}$ were considered. For hcp type facets, the following supercells were used: $\mathrm{p}(3 \times 3)$ of four layers for $\mathrm{Co}(0001), \mathrm{p}(4 \times 4)$ of four layers for $\mathrm{Co}(10-11), \mathrm{p}(4 \times 4)$ of six layers for $\mathrm{Co}(10-10)$, $\mathrm{p}(3 \times 3)$ of four layers for $\mathrm{Co}(10-12)$, and $\mathrm{p}(4 \times 4)$ of four layers for $\mathrm{Co}(11-20)$; for fcc type surfaces: $\mathrm{p}(3 \times 3)$ of four layers for $\mathrm{Co}(111)$ and $\mathrm{Cu}(111), \mathrm{p}(3 \times 3)$ of four layers for $\mathrm{Co}(100)$ and $\mathrm{Cu}(100), \mathrm{p}(3 \times 4)$ of four layers for $\mathrm{Co}(110)$ and $\mathrm{Cu}(110)$, and $\mathrm{p}(3 \times 3)$ of four layers for $\mathrm{Co}(211)$ and $\mathrm{Cu}(211)$ facets. For the Brillouin zone integration, Monkhorst-Pack meshes of $3 \times 3 \times 1$ and $5 \times 5 \times 1 \mathrm{~K}$-points were used for $\mathrm{Co}$ and $\mathrm{Cu}$, respectively. ${ }^{61}$ Spin-polarized calculations were performed for Co using an initial magnetic moment of $1.63 \mu \mathrm{B}$ per atom. It tuned slightly to: $1.58 \mu \mathrm{B}$ for (0001), 1.70 $\mu \mathrm{B}$ for (10-11), $1.71 \mu \mathrm{B}$ for (10-10), $1.73 \mu \mathrm{B}$ for $(10-12)$,
$1.78 \mu \mathrm{B}$ for (11-20), $1.60 \mu \mathrm{B}$ for (111), 1.69 for (100), 1.69 $\mu \mathrm{B}$ for (110), and $1.69 \mu \mathrm{B}$ for (211).

Adsorption and reaction processes were realized on the upper surface of the slab. Structures were allowed to relax until the forces were lower than $0.015 \mathrm{eV} \AA^{-1}$. Frequencies were computed numerically within the harmonic approximation. A reaction path generator developed by Fleurat-Lessard, Opt'n Path, ${ }^{62}$ together with nudge elastic band procedures (NEB), ${ }^{63,64}$ allowed us to determine the transition-state (TS) structures which were further optimized using the dimer method. ${ }^{65,66}$ All TSs were verified to present a single imaginary frequency whose normal mode corresponds to the reaction coordinate.

For the species adsorbed on the surfaces, Gibbs free energies were approximated by the electronic energies. For gas-phase species, translational and rotational entropy contributions were added at $423 \mathrm{~K}$ (typical experimental temperature) $)^{67,68}$ within the ideal gas and rigid rotator approximations using a homemade script. The electronic structure of radical species were evaluated including spin-polarization.

Definition of Energy Terms. The definitions gathered here are used for the employed energy quantities:

- Adsorption energy of a species $\mathrm{C}_{x} \mathrm{H}_{y} \mathrm{O}_{z}$ on a surface $\mathrm{S}$

$$
\begin{aligned}
& \mathrm{C}_{x} \mathrm{H}_{y} \mathrm{O}_{z}+\mathrm{S} \rightarrow \mathrm{C}_{x} \mathrm{H}_{y} \mathrm{O}_{z} @ \mathrm{~S} \\
& E_{\mathrm{ads}}=E\left(\mathrm{C}_{3} \mathrm{H}_{y} \mathrm{O} @ \mathrm{~S}\right)-E\left(\mathrm{C}_{3} \mathrm{H}_{y} \mathrm{O}\right)-E(\mathrm{~S})
\end{aligned}
$$

where $y$ is in the range $6-8$.

- Binding energy of $\mathrm{H}$ is given relative to $\mathrm{H}_{2}$ while the binding energy of a species $\mathrm{C}_{3} \mathrm{H}_{y} \mathrm{O}$ is given relative to iPrOH $\left(\mathrm{C}_{3} \mathrm{H}_{8} \mathrm{O}\right)$ :

$$
\begin{aligned}
\mathrm{C}_{3} \mathrm{H}_{8} \mathrm{O}+\mathrm{S} \rightarrow \mathrm{C}_{3} \mathrm{H}_{y} \mathrm{O} @ \mathrm{~S}+\frac{(8-y)}{2} \mathrm{H}_{2} \\
\begin{aligned}
\Delta E\left(\mathrm{C}_{3} \mathrm{H}_{y} \mathrm{O}\right)= & E\left(\mathrm{C}_{3} \mathrm{H}_{y} \mathrm{O} @ \mathrm{~S}\right)-E\left(\mathrm{C}_{3} \mathrm{H}_{8} \mathrm{O}\right)-E(\mathrm{~S}) \\
& +\frac{(8-y)}{2} E\left(\mathrm{H}_{2}\right)
\end{aligned}
\end{aligned}
$$

- Reaction energy of $\mathrm{OH}$ or $\mathrm{CH}$ bond scission starting from $\mathrm{C}_{3} \mathrm{H}_{y} \mathrm{O} @ \mathrm{~S}$

$$
\begin{aligned}
\mathrm{C}_{3} \mathrm{H}_{y} \mathrm{O} @ \mathrm{~S}+\mathrm{S} \rightarrow \mathrm{C}_{3} \mathrm{H}_{y-1} \mathrm{O} @ \mathrm{~S}+\mathrm{H} @ \mathrm{~S} \\
\begin{aligned}
\Delta E_{\mathrm{r}}\left(\mathrm{C}_{3} \mathrm{H}_{y} \mathrm{O}\right)= & E\left(\mathrm{C}_{3} \mathrm{H}_{y-1} \mathrm{O} @ \mathrm{~S}\right)+E(\mathrm{H} @ S) \\
& -E\left(\mathrm{C}_{3} \mathrm{H}_{y} \mathrm{O} @ \mathrm{~S}\right)-E(\mathrm{~S})
\end{aligned}
\end{aligned}
$$

- Activation energy of an $\mathrm{OH}$ or $\mathrm{CH}$ bond scission with respect to adsorbed species $\mathrm{C}_{3} \mathrm{H}_{y} \mathrm{O}$

$$
E_{\text {act }}=E(\mathrm{TS} @ S)-E\left(\mathrm{C}_{3} \mathrm{H}_{y} \mathrm{O} @ S\right)
$$

Generalized Coordination Number. GCNs were determined for each adsorption site following the philosophy introduced by Calle-Vallejo et al. ${ }^{32}$ The calculations of the GCNs were performed with a home-written script, which is provided as Supporting Information. It is schematically exemplified on the case of $\mathrm{H}$ adsorbed in a hollow site of the (211) facet (Figure 1). At first, determining the GCN requires identifying the first and the second metallic coordination spheres $\left(\Omega_{1}\right.$ and $\left.\Omega_{2}\right)$ for a given position of an adsorbate. $\Omega_{1}$ includes the metal atoms within a given radius from a given position. $\Omega_{2}$ includes all the metal atoms 

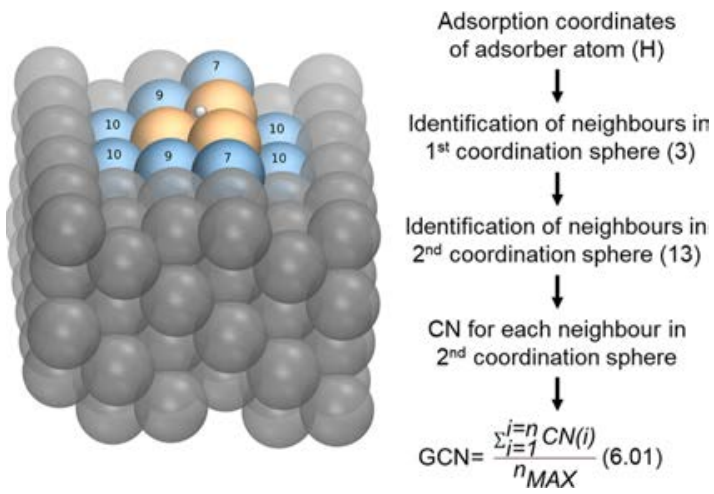

Figure 1. Example of GCN computation for a three-coordinated adsorption position on the (211) surface. Orange atoms represent the first coordination sphere $\Omega_{1}$ of the adsorption site, while blue atoms are the second coordination sphere $\Omega_{2}$. The rest of the slab atoms is marked as transparent gray. Displayed values are the regular coordination numbers $(\mathrm{CNs})$ of the atoms of the second coordination sphere.

coordinated to the metal atoms belonging to $\Omega_{1}$ (also within the same radius), but atoms from $\Omega_{1}$ are not included in $\Omega_{2}$. Then, the coordination number $(\mathrm{CN})$ for all atoms in $\Omega_{2}$ is identified. This radius was set to the shorter metal-metal distance, that is, $2.47 \AA$ for adsorbates on Co surfaces and 2.56 $\AA$ for adsorbates on $\mathrm{Cu}$ surfaces. Finally, the GCN of the given position is calculated as follows

$$
\mathrm{GCN}=\frac{\sum_{i=1}^{i=n} \mathrm{CN}(i)}{n_{\mathrm{MAX}}}
$$

with $n$ equal to the number of neighbors in the second coordination sphere (number of atoms in $\Omega_{2}$ ) and $n_{\operatorname{MAX}}$ the maximal number of neighbors in the second coordination sphere, which depends on the number of neighbors in the first coordination sphere $\Omega_{1}$ (type of adsorption site) and on the metal crystallographic type: $n_{\mathrm{MAX}}$ is defined as the number of atoms that would constitute $\Omega_{2}$ if the atoms of $\Omega_{1}$ were all in the metal bulk (Figure 1). The determination of $n_{\mathrm{MAX}}$ for fcc metals was already reported by Calle-Vallejo et al., ${ }^{32}$ and here we extended it to hcp metals. Values of $n_{\text {MAX }}$ for different sites and crystal types can be found in Table S1.

When a reaction species was adsorbed to the surface via more than one atom, the corresponding GCN was computed as the average of the GCNs for the different anchoring atoms.

\section{RESULTS AND DISCUSSION}

The Gibbs free energy profiles of the dehydrogenation of isopropanol were computed on 9 Co surfaces (hcp and fcc) and $4 \mathrm{Cu}$ surfaces (fcc). While the stable compact (111) facet is clearly the most exposed one on fcc $\mathrm{Co}$ and fcc $\mathrm{Cu}$, noticeably $(10-11)$ is the most exposed facet on hcp Co even though the compact (0001) facet is the most stable one. We systematically investigated the two possible routes illustrated in Scheme 1: (i) Path A (shown in blue) starts with the $\mathrm{OH}$ scission $\left(\mathrm{TS}_{\mathrm{OH}}\right)$, leading to the alkoxy intermediate $\mathrm{iPrO}$, followed by the $\mathrm{CH}$ bond scission $\left(\mathrm{TS}_{\mathrm{OH}-\mathrm{CH}}\right)$, (ii) Path $\mathrm{B}$ (shown in red) inverts the ordering of the bond breaking steps, starting from $\mathrm{CH}$ bond dissociation $\left(\mathrm{TS}_{\mathrm{CH}}\right)$, passing through the hydroxyalkyl intermediate $\mathrm{CH}_{3} \mathrm{COHCH}_{3}$, finishing with the $\mathrm{OH}$ bond scission $\left(\mathrm{TS}_{\mathrm{CH}-\mathrm{OH}}\right)$. The corresponding energy data are shown in Tables S2-S5, Supporting Information.
Scheme 1. Pathways Considered for the Dehydrogenation of Isopropanol (iPrOH) to Acetone $\left(\mathrm{CH}_{3} \mathrm{COCH}_{3}\right)$ with the Coproduction of $\mathrm{H}_{2}$ (Not Shown)

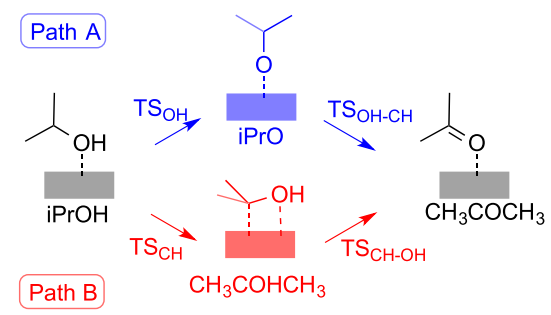

The typical linear scaling relations ${ }^{69}$ used for in silico catalyst design are obtained when the binding energy $(\Delta E)$ of each surface species (shown in Scheme 1) is plotted against the adsorption energy of $\mathrm{O}$ or $\mathrm{C}\left(\Delta E_{\mathrm{O}}\right.$ and $\left.\Delta E_{\mathrm{C}}\right)$ on our series of $\mathrm{Co}$ and $\mathrm{Cu}$ surfaces (Figure S1). The slope $\alpha$ and intercept $\beta$ of the corresponding correlations are reported together with the mean absolute error (MAE), maximal absolute error (MAX), and the determination coefficient $\left(R^{2}\right)$ in Table 1 . The

Table 1. Linear Scaling Relation Parameters (Slope $\alpha$, Intercept $\beta$, MAE, MAX, and Determination Coefficient $R^{2}$ ) Using the Adsorption Energies of $O$ and $C\left(\Delta E_{O}\right.$ and $\left.\Delta E_{C}\right)$ as Descriptors to Predict the Binding Energies of Different Species $\left(\Delta E(X) ; \mathrm{X}=\mathrm{H}\right.$, iPrOH, iPrO, $\mathrm{CH}_{3} \mathrm{COHCH}_{3}$, and $\mathrm{CH}_{3} \mathrm{COCH}_{3}$ )

\begin{tabular}{clrrrrr} 
descriptor & \multicolumn{1}{c}{$\mathrm{X}$} & $\alpha$ & $\beta(\mathrm{eV})$ & $\begin{array}{c}\mathrm{MAE} \\
(\mathrm{eV})\end{array}$ & $\begin{array}{c}\mathrm{MAX} \\
(\mathrm{eV})\end{array}$ & $R^{2}$ \\
$\Delta E_{\mathrm{O}}$ & $\mathrm{H}$ & 0.24 & 1.33 & 0.06 & 0.18 & 0.74 \\
& $\mathrm{iPrOH}$ & 0.11 & -0.04 & 0.12 & 0.24 & 0.15 \\
& $\mathrm{iPrO}$ & 0.47 & 2.49 & 0.09 & 0.18 & 0.85 \\
& $\mathrm{CH}_{3} \mathrm{COCH}_{3}$ & 0.41 & 2.96 & 0.12 & 0.24 & 0.48 \\
& $\mathrm{H}$ & 0.12 & 0.52 & 0.07 & 0.21 & 0.61 \\
& $\mathrm{O}$ & 0.51 & -3.18 & 0.12 & 0.28 & 0.92 \\
& $\mathrm{iPrOH}$ & 0.08 & -0.22 & 0.11 & 0.23 & 0.26 \\
& $\mathrm{CH}_{3} \mathrm{COHCH}_{3}$ & 0.26 & 2.15 & 0.19 & 0.32 & 0.62 \\
& $\mathrm{CH}_{3} \mathrm{COCH}_{3}$ & 0.25 & 1.97 & 0.18 & 0.31 & 0.61
\end{tabular}

determination coefficient $R^{2}$ informs about the correlation fit and is more sensitive to outliers, especially for small slopes. More important is the quality of the estimate of the adsorption energy, which is better reflected by MAE and MAX that directly inform about the distance of the real value to the prediction line. ${ }^{70}$ The binding energy of $\mathrm{iPrO}$ is expected to scale with the adsorption of atomic $\mathrm{O}\left(\Delta E_{\mathrm{O}}\right)$ while the binding energy of $\mathrm{CH}_{3} \mathrm{COHCH}_{3}$ should scale with the one of $\mathrm{C}\left(\Delta E_{\mathrm{c}}\right)$ because they are bound to the metal through $\mathrm{O}$ and (mainly) $\mathrm{C}$, respectively. These linear relations are established processing the combined $\mathrm{Co}$ and $\mathrm{Cu}$ data, yielding a typical MAE below $0.2 \mathrm{eV}$ and MAX below $0.32 \mathrm{eV}$. The obtained slope is in agreement with expectations based on the bondorder of the adsorbed fragments: $\sim 0.5$ for $\mathrm{iPrO}$ and $\sim 0.25$ for $\mathrm{CH}_{3} \mathrm{COHCH}_{3}$. Noticeably, when a similar relation is established on a larger series of transition metals but only on the (111) surface, the slope of the alkoxy/O scaling relation is lower (0.38), and surprisingly, this relation still allows us to predict our structurally diverse set of data with a mean signed error (MSE) of $0.10 \mathrm{eV}$ and a MAX of $0.27 \mathrm{eV}$. On the other hand, predicting the hydroxyalkyl adsorption systematically yields a strong overestimation with a MSE of $-0.27 \mathrm{eV}$. Hence, 
predicting the activity of structurally diverse facets using linear relations established on (111) appears rather hazardous.

$\mathrm{BEP}$ linear relations ${ }^{12,13,71}$ are the second major ingredient for in silico catalysts design. For alcohol dehydrogenation, BEP relations were shown to be effective at predicting $\mathrm{CH}$ and $\mathrm{OH}$ scission barriers with MAE below $0.1 \mathrm{eV}$ and a maximal error contained below $0.3 \mathrm{eV} .{ }^{15,72}$ Processing independently the $\mathrm{CH}$ and $\mathrm{OH}$ scissions data, we obtained the BEP relationships represented with solid lines in Figure 2. The corresponding

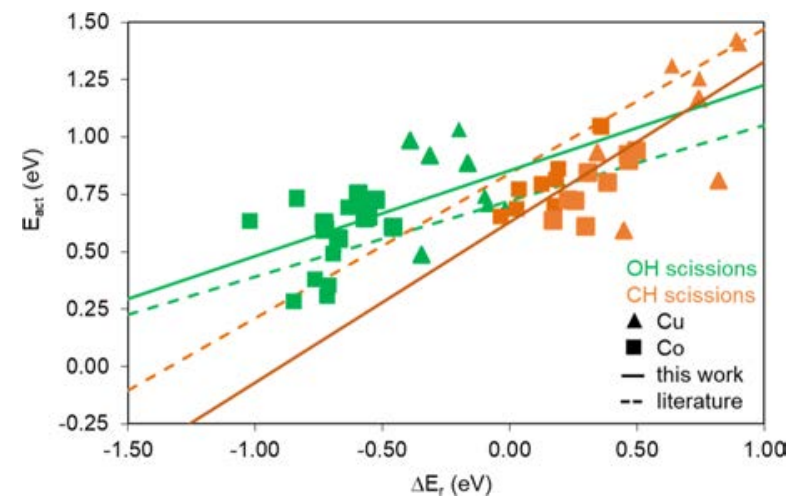

Figure 2. Activation energy $E_{\text {act }}(\mathrm{eV})$ as a function of the reaction energy $\Delta E_{\mathrm{r}}(\mathrm{eV})$ for $\mathrm{OH}$ scissions (green) and the $\mathrm{CH}$ scissions (orange) on $\mathrm{Cu}$ (triangle) and Co (squares) surfaces. Dashed lines correspond to the linear relationships established previously for those scissions on compact surfaces for a series of transition metals, ${ }^{15}$ while the continuous lines correspond to the linear relations obtained with the set of data shown here. BEP linear relationships parameters (slope $\alpha$, intercept $\beta, \mathrm{MAE}, \mathrm{MAX}$, and determination coefficient $R^{2}$ ) are reported in Table S8.

slopes and intercepts are reported in Table S8 together with the related MAE and MAX. These BEP relations perform reasonably well in terms of $\operatorname{MAE}(<0.13 \mathrm{eV})$, but with few errors greater than $0.5 \mathrm{eV}$ as in $\mathrm{TS}_{\mathrm{OH}-\mathrm{CH}}$ on $\mathrm{Cu}(100)$ and $\mathrm{Cu}(110)$. Conversely, the BEP relations formerly established on a set of (111) surfaces $^{15}$ (presented by dashed lines in Figure 2) systematically underestimate activation energies for $\mathrm{OH}$ scissions (MSE $=-0.11 \mathrm{eV}$ or $-10 \%$ ) and overestimate $\mathrm{CH}$ scission barriers ( $\mathrm{MSE}=0.18 \mathrm{eV},+25 \%)$. Limited performance of the linear scaling relations combined with the

(a) $\mathrm{Cu}$

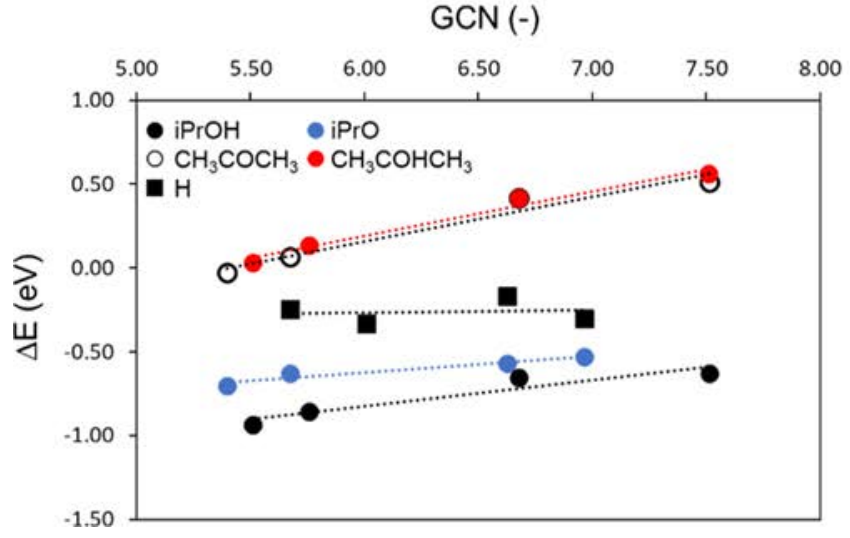

above-described systematic errors in BEP relations strongly question the use of volcano plots established on a given facet to predict the activity on other facets for alcohol dehydrogenation. Besides, retro-engineering the best combination of the metal and facet based on $\mathrm{C}$ and $\mathrm{O}$ adsorption energies is rather cumbersome because these descriptors are energy-based and not structure-based.

The GCN is a structural descriptor that is in a better position than $\Delta E_{\mathrm{O}}$ or $\Delta E_{\mathrm{C}}$ to power the structure engineering. As mentioned above, this structural descriptor not only counts the nearest neighbors, but also takes into account their coordination because nearest-neighbor participation is weighted by their coordination numbers. It can be applied to any coordination site, ${ }^{32}$ and ranges from 5.40 to 7.93 for our set of surfaces.

For a given species on a given metal, the adsorption energy is well described by the GCN descriptor as shown in Figure 3. The corresponding MAE and MAX values are contained below 0.08 and $0.19 \mathrm{eV}$, respectively (see Table S10). These relations perform better than the energy-based relations (see Tables S6-S8). Similarly, using the GCN as a descriptor, low errors are obtained for the transition-state adsorption, as shown in Figure 4, with MAE $<0.15 \mathrm{eV}$ and $\mathrm{MAX}<0.24 \mathrm{eV}$ (see Table S12). The only exception is $\mathrm{TS}_{\mathrm{OH}}$ on Co with a MAX of 0.43 $\mathrm{eV}$, which corresponds to the (211) stepped surface. These structural linear relations are not only nicely performing statistically but are also very informative. The intercept is an indicator of the strength of adsorption. ${ }^{34}$ Typically, the lower intercept values systematically observed on Co in comparison with $\mathrm{Cu}$ can be traced back to the stronger oxophilicity of Co. More importantly here, the slope is a simple means to probe the structure sensitivity providing insights into the catalytic reaction. The adsorption of $\mathrm{iPrOH}$ through the oxygen lone pair on top of a metallic atom makes this adsorption rather structure-insensitive with a slope of 0.16 both on $\mathrm{Co}$ and $\mathrm{Cu}$. Acetone is weakly bonded on $\mathrm{Cu}$ and $\mathrm{Co}$, but its adsorption is structure-sensitive with an identical slope of 0.27 on both metals. Going further, $\mathrm{H}$ and $\mathrm{iPrO}$ are adsorbed via several metal/H or metal/O bonds, a number that depends on the type of surface. Nevertheless, both are completely structureinsensitive with slopes ranging between -0.05 and 0.11 , indicating that the geometric suggestion of several bonds is less

(b) Co

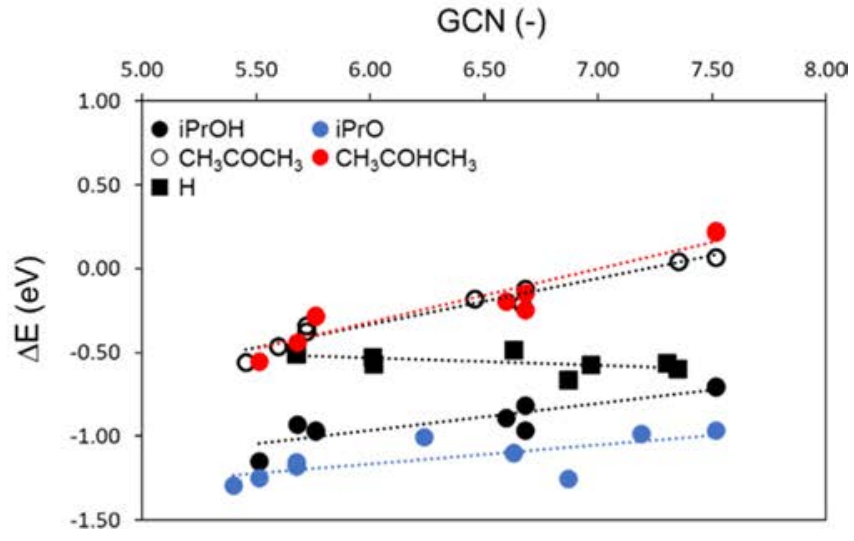

Figure 3. Binding energy ( $\Delta E$ in $\mathrm{eV}$ ) on (a) $\mathrm{Cu}$ and (b) Co surfaces as a function of the GCN of the adsorption position of iPrOH (black dot), $\mathrm{CH}_{3} \mathrm{COCH}_{3}$ (black circle), $\mathrm{H}$ (black square), $\mathrm{PrO}$ (blue dot), and $\mathrm{CH}_{3} \mathrm{COHCH}_{3}$ (red dot). The corresponding linear regressions are shown with dotted lines. Their slopes $\alpha$, intercepts $\beta$, MAE, MAX, and determination coefficient $R^{2}$ are reported in Table S10. 
(a) $\mathrm{Cu}$

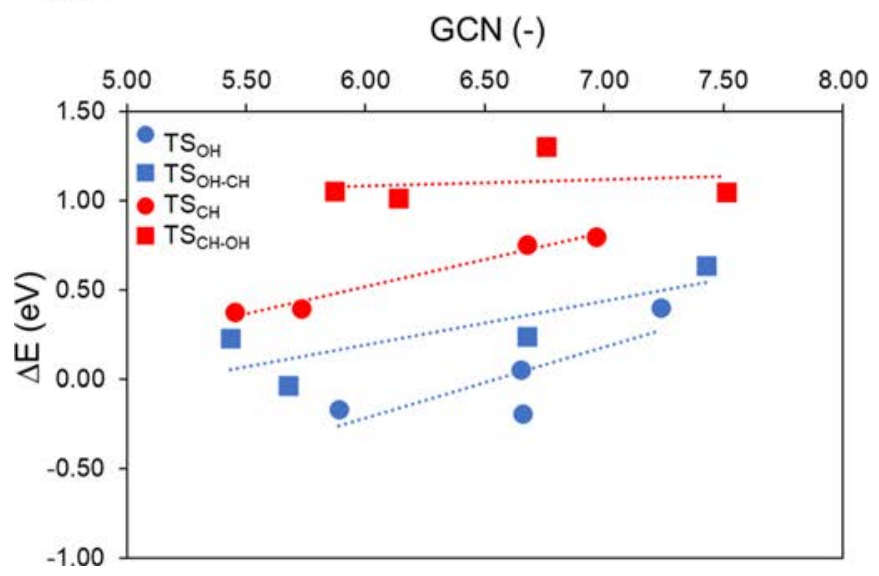

(b) Co

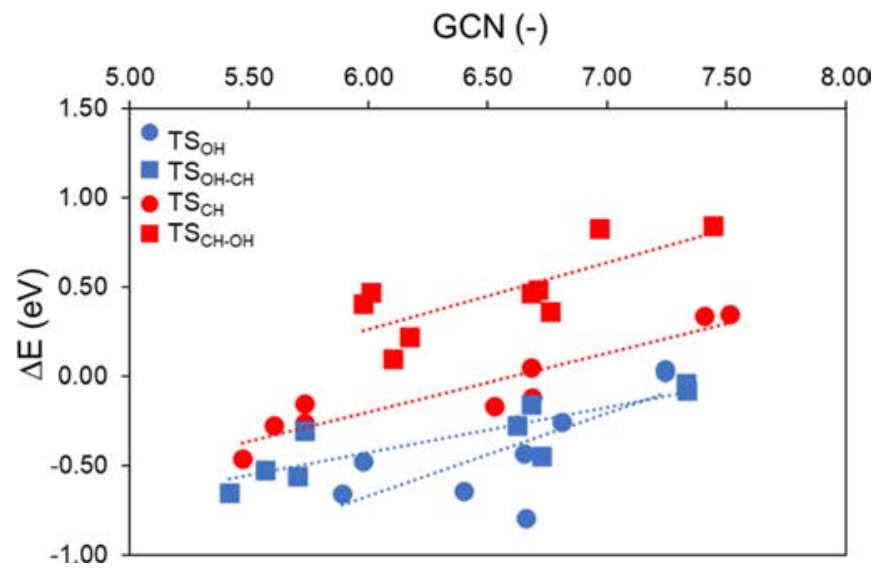

Figure 4. Binding energy $(\Delta E$ in $\mathrm{eV})$ on (a) $\mathrm{Cu}$ and (b) Co surfaces as a function of the GCN of the adsorption position of the transition states $\mathrm{TS}_{\mathrm{OH}}$ (blue dot), $\mathrm{TS}_{\mathrm{OH}-\mathrm{CH}}$ (blue square), $\mathrm{TS}_{\mathrm{CH}}$ (red dot), and $\mathrm{TS}_{\mathrm{CH}-\mathrm{OH}}$ (red square). The corresponding linear regressions are shown with a dotted line. Their slopes $\alpha$, intercepts $\beta$, MAE, MAX, and determination coefficient $R^{2}$ are reported in Table S12.

important than the formal unity valency of the adsorbate. Finally, the hydroxyalkyl $\mathrm{CH}_{3} \mathrm{CHOCH}_{3}$ is structure-sensitive with a slope of 0.32 on $\mathrm{Co}$ and 0.26 on $\mathrm{Cu}$. Regarding the transition states, they emerge as generally more structure sensitive than the intermediates with slopes as high as 0.46 (see Figure 4 and Table S12). The $\mathrm{CH}$ breakings are less structuresensitive than most $\mathrm{OH}$ breakings with the noticeable exception of $\mathrm{TS}_{\mathrm{CH}-\mathrm{OH}}$ on $\mathrm{Cu}$, which is the only one that is completely structure-insensitive with a slope of 0.04 .

These structure-based relations show a contrasted picture along the alcohol dehydrogenation pathways: some intermediates and transition states are strongly structure-sensitive while others are structure-insensitive. Thus, the relation between the overall activity and the structure is not obvious without estimating kinetic parameters. One of the most convenient ways to assess the activity is to rely on the simplified model of the energetic span. ${ }^{73}$ We have identified the TOF-limiting intermediate and TOF-limiting transition state along the alkoxy and hydroxyalkyl pathways (Scheme 1) on $\mathrm{Cu}$ and $\mathrm{Co}$. Their adsorption energy versus GCN relations were used to obtain the energy span and the corresponding predicted TOF for a given GCN within our range of investigation. A detailed example is given in Supporting Information, section S5.3. The plot of the predicted TOF as a function of the GCN (Figure 5) clearly shows that alcohol

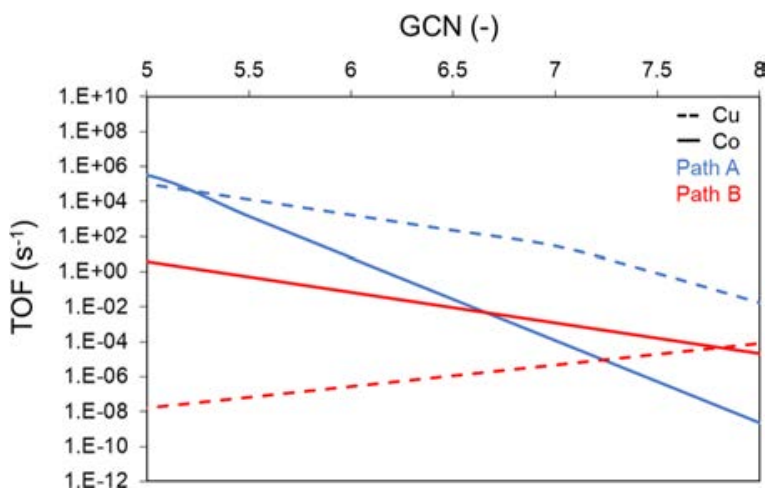

Figure 5. Predicted TOF $\left(\mathrm{s}^{-1}\right)$ for $\mathrm{iPrOH}$ dehydrogenation on $\mathrm{Cu}$ (dashed line) and Co (solid line) for Path A (blue) and Path B (red) as a function of the GCN. dehydrogenation is structure-sensitive: the catalytic activity increases when the GCN decreases, in a greater extent on Co than on $\mathrm{Cu}$. The hydroxyalkyl pathway on $\mathrm{Cu}$ is the only exception to this trend but it is predicted poorly active. Finally, to reach the highest activity, building $\mathrm{Cu}$-based catalysts with sites of a very low GCN appears as a good strategy. Low GCN sites on $\mathrm{Cu}$ were already identified as exposed and active in $\mathrm{CO}_{2}$ electroreduction. ${ }^{74,75}$ Recently, this was found also for the $\mathrm{AAD}$ reaction, where the most active $\mathrm{Cu} / \mathrm{ZrO}_{2}$ was found to be the one with the smallest metal crystallite size, hence exposing the largest amount of low-coordinated sites. ${ }^{48}$ Otherwise, if using Co, the GCN of exposed sites should be lower than 5.5 to achieve good performance. Such sites are hardly exposed on the investigated facets and would require defects (typically adatoms), very small NPs, or correspond to corners on NPs.

\section{CONCLUSIONS}

We have investigated isopropanol dehydrogenation on the most stable surfaces of hcp and fcc $\mathrm{Co}$ and $\mathrm{fcc} \mathrm{Cu}$. As our analysis has shown, for this reaction in silico design cannot be achieved neither with scaling relations nor with BEP relations, which are built only on energy-based descriptors. Hence, we decided to employ a structural descriptor, that is the GCN. Using this descriptor, it has been possible to relate the energy of intermediates and transition states to the GCN values for the adsorption sites, which has led to the conclusion that lowcoordinated sites are desirable when using $\mathrm{Co}$ and $\mathrm{Cu}$ to perform the AAD reaction. This study demonstrates that the GCN is a powerful descriptor to probe the structure sensitivity of reactions, to analyze activity of various active sites, and thus to determine the geometrical properties of active sites that should be maximally exposed. This is essential to improve the performance of supported metal catalysts.

\section{ASSOCIATED CONTENT}

Coordinates of the optimized structures (ZIP)

Python Script to compute the GCN (ZIP) 
Computational details; alcohol dehydrogenation data; energy scaling relations; BEP relations; and adsorption of intermediates and transition states and catalytic activity with GCN as a descriptor (PDF)

\section{AUTHOR INFORMATION}

\section{Corresponding Author}

Carine Michel - Université Lyon, ENS de Lyon, CNRS UMR 5182, Laboratoire de Chimie, 69342 Lyon, France; (1) orcid.org/0000-0002-4501-7194;

Email: carine.michel@ens-lyon.fr

\section{Authors}

Kamila Kaźmierczak - Université Lyon, ENS de Lyon, CNRS UMR 5182, Laboratoire de Chimie, 69342 Lyon, France; Université Lyon, Université Claude Bernard Lyon 1, CNRS, IRCELYON, F-69626 Villeurbanne, France

Paul Clabaut - Université Lyon, ENS de Lyon, CNRS UMR 5182, Laboratoire de Chimie, 69342 Lyon, France; (1) orcid.org/0000-0003-4982-8629

Ruben Staub - Université Lyon, ENS de Lyon, CNRS UMR 5182, Laboratoire de Chimie, 69342 Lyon, France

Noémie Perret - Université Lyon, Université Claude Bernard Lyon 1, CNRS, IRCELYON, F-69626 Villeurbanne, France; ○ orcid.org/0000-0003-4976-5189

Stephan N. Steinmann - Université Lyon, ENS de Lyon, CNRS UMR 5182, Laboratoire de Chimie, 69342 Lyon,

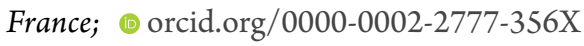

Complete contact information is available at:

https://pubs.acs.org/10.1021/acs.jpcc.1c01746

\section{Notes}

The authors declare no competing financial interest.

\section{ACKNOWLEDGMENTS}

This work was done as a part of the ANR TANOPOL project (ANR-15-CE07-0011-01). The computations were performed using HPC resources from GENCI-CINES (Grant 2018A0050800609) and from the PSMN Data Center, which was financially supported by the SYSPROD project and the AXELERA Pôle de Compétitivité.

\section{REFERENCES}

(1) Nørskov, J. K.; Bligaard, T.; Rossmeisl, J.; Christensen, C. H. Towards the Computational Design of Solid Catalysts. Nat. Chem. 2009, 1, 37-46.

(2) Somorjai, G. A.; Li, Y. Major Successes of Theory-andExperiment-Combined Studies in Surface Chemistry and Heterogeneous Catalysis. Top. Catal. 2010, 53, 311-325.

(3) Andersson, M.; Bligaard, T.; Kustov, A.; Larsen, K.; Greeley, J.; Johannessen, T.; Christensen, C.; Norskov, J. Toward Computational Screening in Heterogeneous Catalysis: Pareto-Optimal Methanation Catalysts. J. Catal. 2006, 239, 501-506.

(4) Medford, A. J.; Shi, C.; Hoffmann, M. J.; Lausche, A. C.; Fitzgibbon, S. R.; Bligaard, T.; Nørskov, J. K. CatMAP: A Software Package for Descriptor-Based Microkinetic Mapping of Catalytic Trends. Catal. Lett. 2015, 145, 794-807.

(5) Abild-Pedersen, F. Computational Catalyst Screening: Scaling, Bond-Order and Catalysis. Catal. Today 2016, 272, 6-13.

(6) Holewinski, A.; Xin, H.; Nikolla, E.; Linic, S. Identifying Optimal Active Sites for Heterogeneous Catalysis by Metal Alloys Based on Molecular Descriptors and Electronic Structure Engineering. Curr. Opin. Chem. Eng. 2013, 2, 312-319.
(7) Abild-Pedersen, F.; Greeley, J.; Studt, F.; Rossmeisl, J.; Munter, T. R.; Moses, P. G.; Skúlason, E.; Bligaard, T.; Nørskov, J. K. Scaling Properties of Adsorption Energies for Hydrogen-Containing Molecules on Transition-Metal Surfaces. Phys. Rev. Lett. 2007, 99, 016105.

(8) Jones, G.; Bligaard, T.; Abild-Pedersen, F.; Nørskov, J. K. Using Scaling Relations to Understand Trends in the Catalytic Activity of Transition Metals. J. Phys.: Condens. Matter 2008, 20, 064239.

(9) Montemore, M. M.; Medlin, J. W. Site-Specific Scaling Relations for Hydrocarbon Adsorption on Hexagonal Transition Metal Surfaces. J. Phys. Chem. C 2013, 117, 20078-20088.

(10) Greeley, J. Theoretical Heterogeneous Catalysis: Scaling Relationships and Computational Catalyst Design. Annu. Rev. Chem. Biomol. Eng. 2016, 7, 605-635.

(11) Bronsted, J. N. Acid and Basic Catalysis. Chem. Rev. 1928, 5, 231-338.

(12) Bell, R. P.; Hinshelwood, C. N. The Theory of Reactions Involving Proton Transfers. Proc. R. Soc. London, Ser. A 1936, 154, 414-429.

(13) Evans, M. G.; Polanyi, M. Inertia and Driving Force of Chemical Reactions. Trans. Faraday Soc. 1938, 34, 11-24.

(14) Bligaard, T.; Nørskov, J. K.; Dahl, S.; Matthiesen, J.; Christensen, C. H.; Sehested, J. The Brønsted-Evans-Polanyi relation and the volcano curve in heterogeneous catalysis. J. Catal. 2004, 224, 206-217.

(15) Wang, T.; Ibañez, J.; Wang, K.; Fang, L.; Sabbe, M.; Michel, C.; Paul, S.; Pera-Titus, M.; Sautet, P. Rational Design of Selective Metal Catalysts for Alcohol Amination with Ammonia. Nat. Catal. 2019, 2, 773-779.

(16) Wang, S.; Petzold, V.; Tripkovic, V.; Kleis, J.; Howalt, J. G.; Skúlason, E.; Fernández, E. M.; Hvolbæk, B.; Jones, G.; Toftelund, A.; et al. Universal Transition State Scaling Relations for (de)Hydrogenation over Transition Metals. Phys. Chem. Chem. Phys. 2011, 13, 20760-20765.

(17) Wang, S.; Temel, B.; Shen, J.; Jones, G.; Grabow, L. C.; Studt, F.; Bligaard, T.; Abild-Pedersen, F.; Christensen, C. H.; Nørskov, J. K. Universal Brønsted-Evans-Polanyi Relations for C-C, C-O, C-N, N-O, N-N, and O-O Dissociation Reactions. Catal. Lett. 2011, 141, 370373.

(18) Zaffran, J.; Michel, C.; Delbecq, F.; Sautet, P. Trade-Off between Accuracy and Universality in Linear Energy Relations for Alcohol Dehydrogenation on Transition Metals. J. Phys. Chem. C 2015, 119, 12988-12998.

(19) Vojvodic, A.; Nørskov, J. K. New Design Paradigm for Heterogeneous Catalysts. Natl. Sci. Rev. 2015, 2, 140-143.

(20) Pérez-Ramírez, J.; López, N. Strategies to Break Linear Scaling Relationships. Nat. Catal. 2019, 2, 971-976.

(21) Zhao, Z.-J.; Liu, S.; Zha, S.; Cheng, D.; Studt, F.; Henkelman, G.; Gong, J. Theory-Guided Design of Catalytic Materials Using Scaling Relationships and Reactivity Descriptors. Nat. Rev. Mater. 2019, 4, 792-804.

(22) Khorshidi, A.; Violet, J.; Hashemi, J.; Peterson, A. A. How Strain Can Break the Scaling Relations of Catalysis. Nat. Catal. 2018, 1, 263-268.

(23) Kyriakou, G.; Boucher, M. B.; Jewell, A. D.; Lewis, E. A.; Lawton, T. J.; Baber, A. E.; Tierney, H. L.; Flytzani-Stephanopoulos, M.; Sykes, E. C. H. Isolated Metal Atom Geometries as a Strategy for Selective Heterogeneous Hydrogenations. Science 2012, 335, 12091212.

(24) Darby, M. T.; Stamatakis, M.; Michaelides, A.; Sykes, E. C. H. Lonely Atoms with Special Gifts: Breaking Linear Scaling Relationships in Heterogeneous Catalysis with Single-Atom Alloys. J. Phys. Chem. Lett. 2018, 9, 5636.

(25) Ruppert, A. M.; Jędrzejczyk, M.; Potrzebowska, N.; Kaźmierczak, K.; Brzezińska, M.; Sneka-Płatek, O.; Sautet, P.; Keller, N.; Michel, C.; Grams, J. Supported gold-nickel nano-alloy as a highly efficient catalyst in levulinic acid hydrogenation with formic acid as an internal hydrogen source. Catal. Sci. Technol. 2018, 8, 4318-4331. 
(26) Kauppinen, M. M.; Korpelin, V.; Verma, A. M.; Melander, M. M.; Honkala, K. Escaping Scaling Relationships for Water Dissociation at Interfacial Sites of Zirconia-Supported $\mathrm{Rh}$ and $\mathrm{Pt}$ Clusters. J. Chem. Phys. 2019, 151, 164302.

(27) Schoenbaum, C. A.; Schwartz, D. K.; Medlin, J. W. Controlling the Surface Environment of Heterogeneous Catalysts Using SelfAssembled Monolayers. Acc. Chem. Res. 2014, 47, 1438-1445.

(28) Ortuño, M. A.; López, N. Creating Cavities at PalladiumPhosphine Interfaces for Enhanced Selectivity in Heterogeneous Biomass Conversion. ACS Catal. 2018, 8, 6138-6145.

(29) Ká́mierczak, K.; Ramamoorthy, R. K.; Moisset, A.; Viau, G.; Viola, A.; Giraud, M.; Peron, J.; Sicard, L.; Piquemal, J.-Y.; Besson, M.; et al. Importance of the Decoration in Shaped Cobalt Nanoparticles in the Acceptor-Less Secondary Alcohol Dehydrogenation. Catal. Sci. Technol. 2020, 10, 4923.

(30) Van Santen, R. A. Complementary Structure Sensitive and Insensitive Catalytic Relationships. Acc. Chem. Res. 2009, 42, 57-66.

(31) Zandkarimi, B.; Alexandrova, A. N. Dynamics of Subnanometer Pt Clusters Can Break the Scaling Relationships in Catalysis. J. Phys. Chem. Lett. 2019, 10, 460-467.

(32) Calle-Vallejo, F.; Martínez, J. I.; García-Lastra, J. M.; Sautet, P.; Loffreda, D. Fast Prediction of Adsorption Properties for Platinum Nanocatalysts with Generalized Coordination Numbers. Angew. Chem., Int. Ed. 2014, 53, 8316-8319.

(33) Calle-Vallejo, F.; Tymoczko, J.; Colic, V.; Vu, Q. H.; Pohl, M. D.; Morgenstern, K.; Loffreda, D.; Sautet, P.; Schuhmann, W.; Bandarenka, A. S. Finding Optimal Surface Sites on Heterogeneous Catalysts by Counting Nearest Neighbors. Science 2015, 350, 185189.

(34) Calle-Vallejo, F.; Loffreda, D.; Koper, M. T. M.; Sautet, P. Introducing structural sensitivity into adsorption-energy scaling relations by means of coordination numbers. Nat. Chem. 2015, 7, 403-410.

(35) Calle-Vallejo, F.; Bandarenka, A. S. Enabling Generalized Coordination Numbers to Describe Strain Effects. ChemSusChem 2018, 11, 1824-1828.

(36) Bondue, C. J.; Calle-Vallejo, F.; Figueiredo, M. C.; Koper, M. T. M. Structural Principles to Steer the Selectivity of the Electrocatalytic Reduction of Aliphatic Ketones on Platinum. Nat. Catal. 2019, 2, 243-250.

(37) Zhao, Z.; Chen, Z.; Zhang, X.; Lu, G. Generalized Surface Coordination Number as an Activity Descriptor for CO2 Reduction on Cu Surfaces. J. Phys. Chem. C 2016, 120, 28125-28130.

(38) Angelici, R. J. Hydrogen Storage and Energy Recovery Using Aldehydes and Ketones: A Key Role for Catalysis. ACS Catal. 2011, 1, 772-776.

(39) Fang, W.; Chen, J.; Zhang, Q.; Deng, W.; Wang, Y. Hydrotalcite-Supported Gold Catalyst for the Oxidant-Free Dehydrogenation of Benzyl Alcohol: Studies on Support and Gold Size Effects. Chem.-Eur. J. 2011, 17, 1247-1256.

(40) Shimizu, K.-i.; Sugino, K.; Sawabe, K.; Satsuma, A. OxidantFree Dehydrogenation of Alcohols Heterogeneously Catalyzed by Cooperation of Silver Clusters and Acid-Base Sites on Alumina. Chem.-Eur. J. 2009, 15, 2341-2351.

(41) Shimizu, K.-i.; Kon, K.; Shimura, K.; Hakim, S. S. M. A. Acceptor-free dehydrogenation of secondary alcohols by heterogeneous cooperative catalysis between $\mathrm{Ni}$ nanoparticles and acid-base sites of alumina supports. J. Catal. 2013, 300, 242-250.

(42) Kon, K.; Hakim Siddiki, S. M. A.; Shimizu, K.-i. Size- and Support-Dependent Pt Nanocluster Catalysis for Oxidant-Free Dehydrogenation of Alcohols. J. Catal. 2013, 304, 63-71.

(43) Mitsudome, T.; Mikami, Y.; Ebata, K.; Mizugaki, T.; Jitsukawa, K.; Kaneda, K. Copper Nanoparticles on Hydrotalcite as a Heterogeneous Catalyst for Oxidant-Free Dehydrogenation of Alcohols. Chem. Commun. 2008, 4804.

(44) Shimizu, K.-i.; Kon, K.; Seto, M.; Shimura, K.; Yamazaki, H.; Kondo, J. N. Heterogeneous Cobalt Catalysts for the Acceptorless Dehydrogenation of Alcohols. Green Chem. 2013, 15, 418-424.
(45) Damodara, D.; Arundhathi, R.; Likhar, P. R. Copper Nanoparticles from Copper Aluminum Hydrotalcite: An Efficient Catalyst for Acceptor- and Oxidant-Free Dehydrogenation of Amines and Alcohols. Adv. Synth. Catal. 2014, 356, 189-198.

(46) Zhu, Y.; Shen, M.; Xia, Y.; Lu, M. Copper nanoparticles on dichromium trioxide: a highly efficient catalyst from copper chromium hydrotalcite for oxidant-free dehydrogenation of alcohols. Appl. Organomet. Chem. 2015, 29, 152-156.

(47) Kaźmierczak, K.; Pinel, C.; Loridant, S.; Besson, M.; Michel, C.; Perret, N. Supported Cobalt Catalysts for Acceptorless Alcohol Dehydrogenation. ChemPlusChem 2020, 85, 1315-1324.

(48) Kaźmierczak, K.; Salisu, A.; Pinel, C.; Besson, M.; Michel, C.; Perret, N. Activity of Heterogeneous Supported $\mathrm{Cu}$ and $\mathrm{Ru}$ Catalysts in Acceptor-Less Alcohol Dehydrogenation. Catal. Commun. 2021, $148,106179$.

(49) He, X.; Wang, Y.; Zhang, X.; Dong, M.; Wang, G.; Zhang, B.; Niu, Y.; Yao, S.; He, X.; Liu, H. Controllable in Situ Surface Restructuring of $\mathrm{Cu}$ Catalysts and Remarkable Enhancement of Their Catalytic Activity. ACS Catal. 2019, 9, 2213-2221.

(50) Viola, A.; Peron, J.; Kazmierczak, K.; Giraud, M.; Michel, C.; Sicard, L.; Perret, N.; Beaunier, P.; Sicard, M.; Besson, M.; et al. Unsupported Shaped Cobalt Nanoparticles as Efficient and Recyclable Catalysts for the Solvent-Free Acceptorless Dehydrogenation of Alcohols. Catal. Sci. Technol. 2018, 8, 562-572.

(51) Liu, J.-X.; Su, H.-Y.; Sun, D.-P.; Zhang, B.-Y.; Li, W.-X. Crystallographic Dependence of CO Activation on Cobalt Catalysts: HCP versus FCC. J. Am. Chem. Soc. 2013, 135, 16284-16287.

(52) Chen, Q.; Svenum, I.-H.; Qi, Y.; Gavrilovic, L.; Chen, D.; Holmen, A.; Blekkan, E. A. Potassium adsorption behavior on hcp cobalt as model systems for the Fischer-Tropsch synthesis: a density functional theory study. Phys. Chem. Chem. Phys. 2017, 19, 1224612254

(53) Kresse, G.; Hafner, J. Ab initiomolecular dynamics for liquid metals. Phys. Rev. B: Condens. Matter Mater. Phys. 1993, 47, 558-561.

(54) Kresse, G.; Furthmüller, J. Efficient iterative schemes forab initiototal-energy calculations using a plane-wave basis set. Phys. Rev. B: Condens. Matter Mater. Phys. 1996, 54, 11169-11186.

(55) Perdew, J. P.; Burke, K.; Ernzerhof, M. Generalized Gradient Approximation Made Simple. Phys. Rev. Lett. 1996, 77, 3865-3868.

(56) Steinmann, S. N.; Corminboeuf, C. A Generalized-Gradient Approximation Exchange Hole Model for Dispersion Coefficients. J. Chem. Phys. 2011, 134, 044117.

(57) Steinmann, S. N.; Corminboeuf, C. Comprehensive Benchmarking of a Density-Dependent Dispersion Correction. J. Chem. Theory Comput. 2011, 7, 3567-3577.

(58) Gautier, S.; Steinmann, S. N.; Michel, C.; Fleurat-Lessard, P.; Sautet, P. Molecular Adsorption at $\mathrm{Pt}(111)$. How Accurate Are DFT Functionals? Phys. Chem. Chem. Phys. 2015, 17, 28921-28930.

(59) Blöchl, P. E. Projector Augmented-Wave Method. Phys. Rev. B: Condens. Matter Mater. Phys. 1994, 50, 17953-17979.

(60) Kresse, G.; Joubert, D. From Ultrasoft Pseudopotentials to the Projector Augmented-Wave Method. Phys. Rev. B: Condens. Matter Mater. Phys. 1999, 59, 1758-1775.

(61) Monkhorst, H. J.; Pack, J. D. Special Points for Brillouin-Zone Integrations. Phys. Rev. B: Solid State 1976, 13, 5188-5192.

(62) Fleurat-Lessard, P. A Chemist View on Reaction Path Determination. http://pfleurat.free.fr/ReactionPath.php.

(63) Henkelman, G.; Uberuaga, B. P.; Jónsson, H. A Climbing Image Nudged Elastic Band Method for Finding Saddle Points and Minimum Energy Paths. J. Chem. Phys. 2000, 113, 9901-9904.

(64) Sheppard, D.; Terrell, R.; Henkelman, G. Optimization Methods for Finding Minimum Energy Paths. J. Chem. Phys. 2008, $128,134106$.

(65) Henkelman, G.; Jónsson, H. A Dimer Method for Finding Saddle Points on High Dimensional Potential Surfaces Using Only First Derivatives. J. Chem. Phys. 1999, 111, 7010-7022.

(66) Kästner, J.; Sherwood, P. Superlinearly Converging Dimer Method for Transition State Search. J. Chem. Phys. 2008, 128, 014106. 
(67) Kaźmierczak, K.; Ramamoorthy, R. K.; Moisset, A.; Viau, G.; Viola, A.; Giraud, M.; Peron, J.; Sicard, L.; Piquemal, J.-Y.; Besson, M.; Perret, N.; Michel, C. Importance of the Decoration in Shaped Cobalt Nanoparticles in the Acceptor-Less Secondary Alcohol Dehydrogenation. Catal. Sci. Technol. 2020, 10, 4923-4937.

(68) Kaźmierczak, K.; Pinel, C.; Loridant, S.; Besson, M.; Michel, C.; Perret, N. Supported Cobalt Catalysts for Acceptorless Alcohol Dehydrogenation. ChemPlusChem 2020, 85, 1315-1324.

(69) Liu, B.; Greeley, J. Decomposition Pathways of Glycerol via C$\mathrm{H}, \mathrm{O}-\mathrm{H}$, and C-C Bond Scission on Pt(111): A Density Functional Theory Study. J. Phys. Chem. C 2011, 115, 19702-19709.

(70) Sutton, J. E.; Vlachos, D. G. A Theoretical and Computational Analysis of Linear Free Energy Relations for the Estimation of Activation Energies. ACS Catal. 2012, 2, 1624-1634.

(71) Evans, M. G.; Polanyi, M. Further Considerations on the Thermodynamics of Chemical Equilibria and Reaction Rates. Trans. Faraday Soc. 1936, 32, 1333.

(72) Zaffran, J.; Michel, C.; Delbecq, F.; Sautet, P. Towards More Accurate Prediction of Activation Energies for Polyalcohol Dehydrogenation on Transition Metal Catalysts in Water. Catal. Sci. Technol. 2016, 6, 6615-6624.

(73) Kozuch, S.; Martin, J. M. L. The Rate-Determining Step Is Dead. Long Live the Rate-Determining State! ChemPhysChem 2011, 12, 1413-1418.

(74) Dutta, A.; Rahaman, M.; Mohos, M.; Zanetti, A.; Broekmann, P. Electrochemical $\mathrm{CO}_{2}$ Conversion Using Skeleton (Sponge) Type of Cu Catalysts. ACS Catal. 2017, 7, 5431-5437.

(75) Dutta, A.; Rahaman, M.; Luedi, N. C.; Mohos, M.; Broekmann, P. Morphology Matters: Tuning the Product Distribution of $\mathrm{CO} 2$ Electroreduction on Oxide-Derived $\mathrm{Cu}$ Foam Catalysts. ACS Catal. 2016, 6, 3804-3814. 